\title{
Anti-Microbial and Phytochemical Screening of the Seed Extracts of Persea Americana (AVOCADO PEAR)
}

\author{
${ }^{* 1}$ Ilozue N.M., ${ }^{2}$ Ikezu U.P. And ${ }^{2}$ Ugwu Okechukwu P.C. \\ ${ }^{I}$ Department Of Pure And Industrial Chemistry, Nnamdi Azikiwe University Awka, Anambra State, Nigeria. \\ ${ }^{2}$ Department Of Chemical Sciences, Tansian University, Umunya Anambra State, Nigeria.
}

\begin{abstract}
The seed of Persea americana was extracted with four different solvents and subjected to preliminary phytochemical screening which revealed the presence of steroids, alkaloids, saponins, tannins, flavonoids and cardiac glycoside. Antimicrobial activity of the seed extracts against Escherichia coli, Staphylococcus aureus and Salmonella typhi was carried out using the disc diffusion techniques. The ethylacetate extract demonstrated pronounced activity against the test organisms. The activity of methanol extract against $S$. aureus was $(31 \mathrm{~mm})$ while that of petroleum ether was (5mm) against E.coli. However, S. typhi and E. coli were resistant to chloroform and methanol extracts. The activity of ethylactate, chloroform and methanol extracts compared favourably with that of the antibiotics erythromycin used as standard. The antimicrobial activities displayed by the various extracts could be attributed to the presence of secondary metabolites identified in the phytochemical screening and also signifies the potential of Persea americana seed as an anti-microbial therapeutic agent.

Keywords:Persea americana, antibiotics, erythromycin, anti-microbial and phytochemicals.
\end{abstract}

\section{Introduction}

Medicinal plants have continued to attract attention in the global search for effective antimicrobial agents that can combat pathogens that have been rendering many conventional drugs obsolete in the treatment of infections [1, 2, 3 and 4]. In recent years, secondary plant metabolites; alkaloids, saponins, tannins, steroids and terpenoids which are the bioactive constituents of plants with pharmacological activities have been extensively investigated as source of medicinal agents [6, 7, 8 and 9]. This has brought a resurgence of interest in the herbal remedies and many drugs have been developed based on these secondary metabolites and their derivatives [2 and 4].

Persea americana(Lauraceae) is one of the 150 varieties of pear. The tree is widely cultivated in tropical and subtropical areas with a height of about $60-80$ feet [10,11 and 12]. It has a green to black knobby egg shaped fruit with a lesthery skin and a large seed of about $5-6 \mathrm{~cm}$. The leaves are evergreen and the flowers unisexual [11 and 10]. Avocado pear is a good source of fiber and high fiber intake lowers the risk of cardiovascular disease, cancer, hypertension as well as obesity. The seed has a diverse application in ethno-medicine, raging from treatment of diarrhoea, dysentery, toothache, ulcer, cholesterol decreasing, prevention of cardiovascular diseases as well as skin beautification [8 and 10]. The seed is also rich in tannins and carotenoids which were shown to inhibit the in-vitro growth of prostate cancer cell lines [5, 7 and 12]. Persea americana leaf have also been reported to possess anti-inflammatory, antihypertensive and analgesic activities $[9,10$ and 11]. The tree in its totality has high medical value.

\section{PREPARATION OF MATERIALS}

\section{Material And Methods}

The fruits of avocado pear were cut into half and the seeds removed. It was thoroughly washed, cut into small sizes and dried at room temperature for five days. It was ground to fine powder and weighed with a weighing machine.

\section{EXTRACTION}

The powdered material $(200 \mathrm{~g})$ was weighed into four different conical flasks and macerated with four different solvents: methanol, ethylacetate, chloroform and petroleum ether. This was left to stand for 24h [9]. After which it was filtered using whatmann filter paper and the various extracts obtained were concentrated in a rotaryevaporator at $40^{\circ} \mathrm{C}$. The small amounts of the various extracts obtained were stored in a refrigerator for use.

\section{PHYTOCHEMICAL SCREENING}

Phytochemical screening of the four extracts was carried out to identify the constituents, using standard phytochemical methods as described by [10]. The analysis involved detection of alkaloids, saponin, steroids, flavonoids, tannins and cardiac glycoside. 


\section{TEST ORGANISMS}

The test organisms are gram-negative Escherichia coli, gram-negative Salmonella typhiand gram positive Staphylococcus aureus. Three bacteria pure culture isolates that were obtained from Department of Microbiology, Nnamdi Azikiwe University Awka-Nigeria.

\section{DETERMINATION OF ANTIMICROBIAL ACTIVITY}

Preparation of medium:- $28 \mathrm{~g}$ of nutrient agar was weighed and dissolved in $1000 \mathrm{ml}$ of water in a conical flask. The solution was sterilized at $120^{\circ} \mathrm{C}$ for $15 \mathrm{~m}$ in autoclave, allowed to cool to about $45^{\circ} \mathrm{C} .20 \mathrm{ml}$ was dispensed in each petri-dish and left to gel as described by [11].

Preparation of disc: Discs were prepared using whatmann filter paper which was sterilized by autoclaving at $180^{\circ} \mathrm{C}$ for $1 \mathrm{~h}$. The Discs were allowed to cool and soaked in the extracts overnight.

Procedure:- Each of the test organisms were streaked on the dishes inoculated with the test organism and incubated for $24 \mathrm{~h}$ at $37^{\circ} \mathrm{C}$. An antibiotic disc of erythromycin was used as control and was also incubated at $37^{\circ} \mathrm{C}$ for $24 \mathrm{~h}$. After which the plates were examined for clear zones of microbial activity. The activity was expressed as the mean diameter of inhibition Zones $(\mathrm{mm})$ produced by the seed extracts.

\section{Results}

Table 1: Phytochemical screening of Persea americana seed extracts

\begin{tabular}{|l|l|l|l|l|l|}
\hline S/NO & Phytochemicals & Methanol & Ethylacetate & Chloroform & Petroleum ether \\
\hline 1. & Alkaloids & + & + & + & - \\
\hline 2. & Steroids & + & + & + & + \\
\hline 3. & Saponin & + & + & + & + \\
\hline 4. & Flavonoids & + & + & - & - \\
\hline 5. & Tannins & + & + & - & - \\
\hline 6. & Cardiac glycoside & + & + & - & - \\
\hline
\end{tabular}

The preliminary phytochemical screening revealed that the four extracts contain steroids and saponins while tannins, flavonoids and cardiac glycoside were present only in methanol and ethylacetate extracts.

Table 2: Antimicrobial activity of Persea americana seed extracts on zones of inhibition (mm) of test microorganisms.

\begin{tabular}{|l|l|l|l|l|l|}
\hline Test organisms & PE & CF & EA & ME & Erythromycin \\
\hline S. aureus & 14 & 27 & 30 & 31 & 27 \\
\hline S.typhi & 8 & 0 & 14 & 0 & 0 \\
\hline E.coli & 5 & 0 & 15 & 0 & 0 \\
\hline
\end{tabular}

Key: $\mathrm{PE}=$ petroleum ether, $\mathrm{CF}=$ chloroform, $\mathrm{ME}=$ methanol and $\mathrm{EA}=$ Ethylacetate.

The petroleum ether extract exhibited activity on all the test organisms, producing zones of inhibition ranging from $5-14 \mathrm{~mm}$ and also ethylacetate extract producing from $14-30 \mathrm{~mm}$. The activities of methanol and chloroform extracts were potent only against S.aureus $(31 \mathrm{~mm}$ and $27 \mathrm{~mm}$ ) while that of ethyl-acetate was least against E.coli (5mm). However S.typhi and E.coli were resistant to chloroform and methanol extracts.

\section{Discussion}

The solvent extracts had demonstrated antimicrobial activity against the test organisms. The ethyl acetate extract had antimicrobial activity against the three test organisms especially against $S$. aureus $(30 \mathrm{~mm})$. It had a pronounced activity against the gram negative E. coli $(15 \mathrm{~mm})$ and S.typhi $(14 \mathrm{~mm})$ when compared to other extracts. Differences in polarity among the various solvents are perhaps responsible for the variation in degree of activity. The activity of ethylacetate and methanol extracts even surpassed that of the standard antibiotic erythromycin.

Moreover, the phytochemical screening revealed the presence of saponin and steroids strongly in the four extracts and also the presence of tannins, flavonoids, alkaloids and cardiac glycoside in mostly the polar solvents. The medical and physiological activities of the seed of Persea americana can be attributed to the presence of these secondary metabolites. It has been known that alkaloids are used for treatment of malaria, diabetes, hypertensionand also used as traquilizer. Saponins are also used as tranquilizer, anti-inflammatory, anti-carcinogenic and anti-lipidemic agents. Hence they have the ability to stimulate the heart muscle. Flavonoids has been known to be synthesized by plants in response to microbial attack. Hence, they are effective antimicrobial substances against a wide array of microorganism when tested invitro [3 and 4]. They are anti-allergic, anti-cancer, anti-inflammatory and so on. Phytotherapeutically, tannin containing plants are used to treat non-specific diarrhoea, inflammations of mouth, throat and slightly injured skin [1,3 and 5].

Hence, that explains the spectra of antimicrobial activities displayed by the seed extracts and signifies the potential of $P$. americana as source of therapeutic agents. 
In conclusion, the activities exhibited by the four extracts against the isolated microbes provide justification for the use of $P$. americana seed in ethnomedicinal practice.

\section{Acknowledgement}

We are grateful to the laboratory technicians in Chemistry and Microbiology Department of Nnamdi Azikiwe University for their immense help in making this analysis successful.

\section{References}

[1]. Cowan, M.M (2002): Plant Products as antimicrobial agents. Clin Microbial. Rev., 12:564-582

[2]. Hill, A.F (1952): Economic Botany : A Textbook of Useful plant and plant products. $2^{\text {nd }}$ ed. McGraw- Hill Book company Inc, New York .Pp 7

[3]. Balandrin M.F., Kjocke A.J and WQurtele D.F (1985): Natural Plant Chemicals sources of Industrial and Pharmaceutics, Human press, New Jersey USA; Pp. 137-141.

[4]. Pacific Health Inform (2005) General Health Products and Alternative Medicine.www.file /1A:/ pacific Health. Info \% 20>> $\% 20$ Products. htm.

[5]. Saver, J.D (1993): Historical Geography of crop plants- A selected rooster. CRC Press, Boca Raton, Florida Pp 1014-1017.

[6]. Pamplora, G.D and Roger M.D (1999). Encyclopedia of Medicinal Plants. Vol. 1 Desktop publishing, spainpp 70-77 PP 719-720.

[7]. Artega J.R, Zhang Q., Huerta S, Go V.l and Herber D. (2005): inhibition of Prostate Cancer cell growth by an avocado extract: role of lipid-soluble bioactive substances. J. Nutr. Biochem 16:23-30.

[8]. Okafor J.C, Arazu R.C, Ibuzo J. Nsofor M. and Okudo A.N (2005) Checklist of medicinal plants of Nigeria and their uses, James Enugu Nigeria. Pp 1-97

[9]. Okentu, I.O and Ani C.J (2001) Phytochemical analysis and antimicrobial Screening of the seed extracts of TetracarpidiumconophorumJ. Chem. Soc, Nigeria, vol 265(1) Pp 1-2.

[10]. Trease, G.E and Evans, W.C (1989): Pharmacognosy. $13^{\text {th }}$ (ed). ELBS/BailliereTindall, London Pp 345-6.

[11]. Akpuaka M.U, Orakwue F.C, Nnaedozie U, Onyeka C.A and Okoli 1 (2003) Preliminary Phytochemical and Anti-bacterial activity Screening of Bryophyllumpinnatum Extracts. J-Chem. Soc. of Nigeria vol. 28, no1, Pp 11-13.

[12]. Adeyemi O.O.,Okpo S.O and Ogunti O.O (2002). Analgesic and anti-inflammatory effect of the aqueous extract of leaves of Perseaamericanamili (lauraceae) Fitroterapia 73:375-380. 